\title{
The Bursting Tendency of Hyphal Tips of Fungi: Presumptive Evidence for a Delicate Balance between Wall Synthesis and Wall Lysis in Apical Growth
}

\author{
By S. BARTNICKI-GARCIA AND ELEANOR LIPPMAN \\ Department of Plant Pathology, University of California, Riverside, \\ California 92502, U.S.A.
}

(Received I6 May 1972; revised I4 July 1972)

\begin{abstract}
SUMMAR Y
A wide diversity of treatments can cause rapid and extensive bursting of hyphal tips of Mucor rouxii. Most hyphal tips from colonies grown on full-strength agar medium burst readily when flooded with distilled water. In contrast, hyphal tips from colonies grown on diluted medium survived flooding with distilled water but succumbed to dilute aqueous solutions (particularly acids, but also neutral salts, EDTA, alcohols, acetone, detergents). Apex bursting was generally inhibited by alkaline solutions but took place at certain concentrations of ethanolamine or $\mathrm{NH}_{4} \mathrm{OH}$. $\mathrm{Mg}^{2+}, \mathrm{Mn}^{2+}$ or $\mathrm{Ca}^{2+}$ caused pronounced swelling of the hyphal apex followed by an occasional burst. Sharp temperature increases also brought about apical disintegration regardless of nutrient concentration.

Colonies of Aspergillus fumigatus, Fusarium sp., Neurospora crassa (wild-type and two morphological mutants), Penicillium claviforme, Rhizoctonia solani and Rhizopus arrhizus also underwent apical bursting when flooded with water or rapidly heated. Schizophyllum commune, several Phytophthora spp., and some morphological mutants of $N$. crass $a$ were refractory.

The bursting of hyphal tips by flooding colonies with water is not simply an osmotic phenomenon; its temperature coefficient $\left(Q_{10} \mathrm{I} \cdot 3\right.$ to $\left.2 \cdot 0\right)$ suggests the additional participation of biochemical reaction(s) as a rate-limiting step in the bursting process. Probably, enzymatic degradation and hence weakening of the wall is a prerequisite for bursting. These observations are offered as circumstantial evidence supporting the following conclusions: (i) the growing tips of fungi have a large wall lytic potential; (ii) the release of this activity during growth must be gradual and delicately co-ordinated with wall synthesis; (iii) this balance can be easily disturbed by a wide variety of external stimuli and the ensuing surge of lytic activity results in the violent disintegration of the hyphal apex.
\end{abstract}

\section{INTRODUCTION}

This investigation is part of a project on the biochemical bases of hyphal morphogenesis in fungi. Since apical growth is the mechanism by which a hyphal tube is generated (Reinhardt, I892; Smith, 1923), one of the main objectives of our study is the elucidation of the biochemical events involved in wall construction at a hyphal tip. A general consideration of the process of wall growth suggests that two different types of biochemical activities are probably essential for apical wall extension: those responsible for adding new polymers (wall synthesis) and those responsible for plasticizing the existing wall fabric (wall lysis) (see Discussion).

Direct quantitative evidence for wall synthesis in the hyphal apex can be obtained by autoradiography (Bartnicki-Garcia \& Lippman, I969; Gooday, I97I ; Katz \& Rosenberger, 


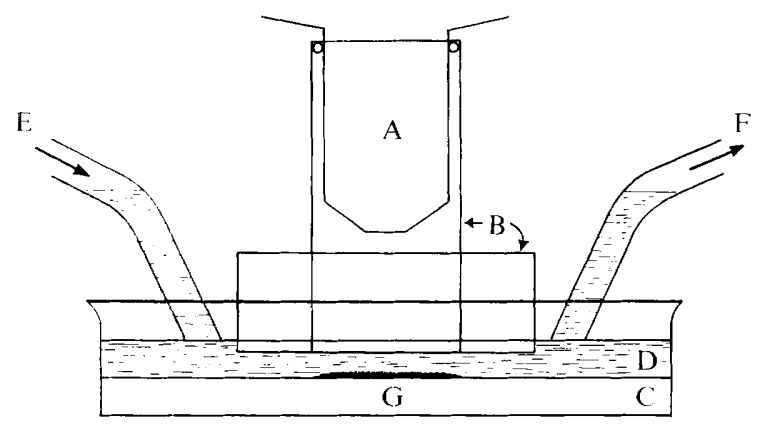

Fig. I. Device used to study hyphal tip bursting at different temperatures. Objective lens (A) fitted with plastic housing (B). Agar layer (C) flooded with running water (D) from a constant-temperature bath entering through inlet tube $(E)$ and removed by suction $(F)$. Fungal colony $(G)$.

1971 a); however, direct evidence for the participation of lytic enzymes in apical wall extension is unavailable.

The present findings, which amplify those made earlier by Robertson (I958, I959) and by Park \& Robinson (I966a) are offered as circumstantial evidence pointing to the existence of a large potential of wall lytic activity in the hyphal apexes and its possible participation in the process of apical wall growth.

\section{METHODS}

Organisms. The principal fungus employed was Mucor rouxii IM-80. Neurospora crassa (wild-type RL3-8A and eight morphological mutants thereof) were supplied by S. Brody of the University of California, San Diego; Rhizopus arrhizus QM-I032 by E. T.Reese from the U.S. Army Laboratories, Natick, Massachusetts, U.S.A.; Phytophthora palmivora (PI I3) by $M$. Aragaki from the University of Hawaii, Honolulu. All other fungi were obtained from the fungal collections of this Department.

Culture media. Ordinary YPG agar (IX.YPG) contained (g/l): Difco yeast extract, 3; Difco peptone, 10; glucose, 20; and Difco Bacto agar, 25. The medium was adjusted to pH 5.5 with $2 \mathrm{~N}-\mathrm{H}_{2} \mathrm{SO}_{4}$. YPG of other concentrations was prepared by increasing or decreasing the concentration of nutrients as indicated. V-8 agar was prepared from V-8 juice (Campbell Soup Co., Camden, New Jersey); $\mathrm{CaCO}_{3}(\mathrm{I} 5 \mathrm{~g}$ ) was added to $1000 \mathrm{ml} \mathrm{V}-8$ juice, mixed and centrifuged at $1000 \mathrm{~g}$ for $\mathrm{I} 5 \mathrm{~min}$. The final medium contained $200 \mathrm{ml}$ of this clear supernatant and $15 \mathrm{~g}$ agar per litre of deionized water. Cultures were grown in $100 \times 15 \mathrm{~mm}$ clear polystyrene Petri dishes containing $15 \mathrm{ml}$ of agar medium. Mucor rouxii and Neurospora crassa RL3-8A (wild) were inoculated from a washed spore suspension by a platinum loop. The inoculum was deposited in the centre of the plate. Cultures were incubated until colonies achieved a diameter of 1 to $1 \cdot 5 \mathrm{~cm}$.

Flooding with water and other dilute solutions. To observe the behaviour of hyphal tips upon addition of distilled water or other solutions, a Reichert Zetopan microscope was fitted with a protective plastic housing attached to the low power $(\times 10)$ objective lens. Two procedures were employed: for routine observation, the colonies were simply flooded with $20 \mathrm{ml}$ of liquid; for experiments on the effect of temperature of the flooding water, a flow system was devised to rapidly equilibrate the temperature of the fungal colony (Fig. I). A large volume of distilled water was maintained at the desired temperature using a refrigerated and heated bath and circulator (Forma Temp Jr.; Model 2096, Forma Sci. Inc., Marietta, Ohio, U.S.A.). The water was pumped at a rate of $200 \mathrm{ml} / \mathrm{min}$ and delivered as a jet near the 

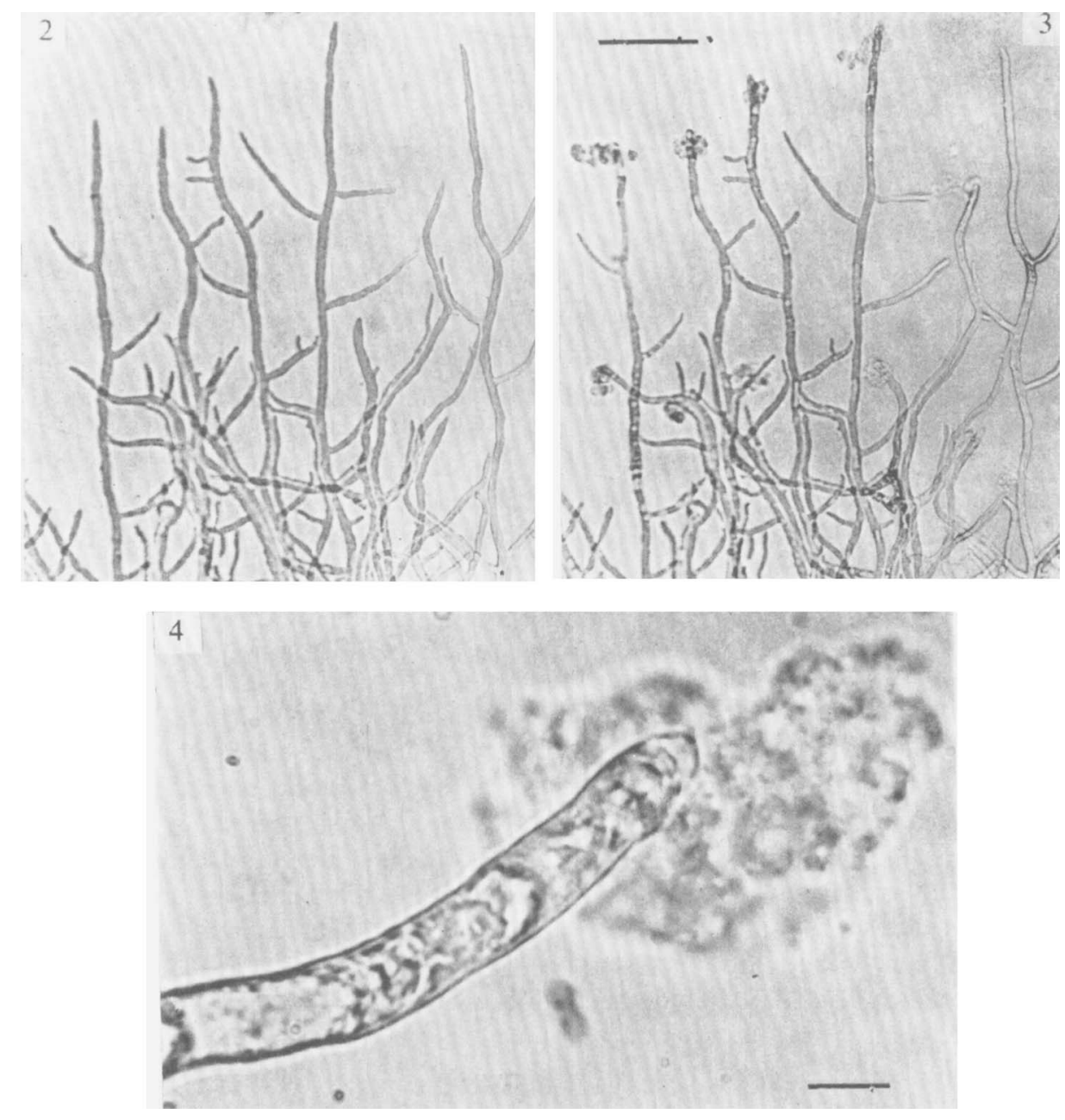

Fig. 2 to 4. Bursting of hyphal tips of Mucor rouxii grown on IX. YPG by flooding colony with distilled water. Fig. 2 taken immediately after addition of water. Fig. 3, 1 min later. (Scale marker $=100 \mu \mathrm{m}$.) Fig. 4, detail of burst tip. (Scale marker $=10 \mu \mathrm{m}$.)

periphery of the colony. Excess water was removed by suction at the opposite side of the colony to permit a rapid stream of water to travel across the fungal colony. Bursting events were scored by hand with a microswitch connected to the event marker of a linear recorder at a chart speed of $6 \mathrm{in} / \mathrm{min}$.

Heat shock. Agar plates with colonies I to $1.5 \mathrm{~cm}$ in diameter were heat shocked by placing the covered dishes in a forced-air oven (Precision Sci. Co. Model 18) at the temperatures and times indicated.

\section{RESULTS}

Apical disintegration by 'osmotic shock'

Mucor rouxii. If a colony of Mucor rouxii, growing on IX. YPG agar, was flooded with distilled water, there was extensive bursting of the hyphal tips around the entire colony margin (Fig. 2 to 4). After addition of the water, there was a short delay, the duration 
Table I. Effect of concentration of growth medium on apical bursting of Mucor rouxii

$\begin{array}{cc}\begin{array}{c}\text { YPG medium } \\ \text { concentration }\end{array} & \text { Bursting* } \\ 4 \times & +++++(4 \mathrm{~s}) \\ 2 \times & +++++(4 \mathrm{~s}) \\ \mathrm{I} \times & ++++(4 \mathrm{~s}) \\ \frac{1}{2} \times & +++(8 \mathrm{~s}) \\ \frac{1}{8} \times & + \\ \frac{1}{8} \times & - \\ \frac{1}{1 \frac{1}{6} \times} & -\end{array}$

* Relative intensity and approximate time of initiation of bursting after flooding the colony with distilled water at $22^{\circ} \mathrm{C}$.

of which depended on temperature, before hyphal tips began to explode; within a few seconds, a barrage of bursting occurred with hyphal tips continuing to burst, with diminishing frequency, for I or 2 min longer.

In most cases, the cytoplasm was violently discharged through a small invisible opening at the apical dome, and often extruded as a long narrow twisting mass. Tips of main hyphae as well as those of side branches were susceptible to bursting but since the fungus is co-enocytic only the primary tip or one side branch (rarely both) disintegrated.

Cultivation conditions greatly affected the ability of the tips to burst upon flooding with distilled water. For example, nutrient concentration was critical. When the fungus was grown on concentrated YPG media, it burst more rapidly and extensively than on dilute media (Table I). At dilutions of X/8. YPG or X/I6. YPG medium good colony growth was obtained but the hyphal tips no longer burst upon addition of distilled water. We made use of this divergent response (see subsequent sections) to test the effect of solutes on apex bursting: inhibition of bursting was tested on colonies grown on IX. YPG medium; promotion of bursting was determined on colonies grown on X/I6. YPG medium.

Colony age was also important. Young colonies, grown on IX.YPG for less than $9 \mathrm{~h}$, and older colonies ( $18 \mathrm{~h}$ or longer) did not readily burst. Also the incidence of bursting was higher in crowded areas of the colony. To minimize this variability of response, tests were made with colonies inoculated and incubated under similar conditions.

Other fungi. A number of fungi were tested and most underwent apical bursting when their colonies, grown on IX. YPG agar, were flooded with distilled water. Extensive bursting similar to that of Mucor rouxii was exhibited by Rhizopus arrhizus, Rhizoctonia solani and Aspergillus fumigatus; colonies of Penicillium claviforme and Fusarium sp. yielded fewer burst tips.

In wild-type Neurospora crassa, bursting was extensive but it took place much more slowly than in Mucor rouxii (see below). Several morphological mutants of $N$. crassa, affected in their pattern of hyphal development (Brody, I972), were also examined. Only the pile and ropy mutants showed a clear tendency to burst though they did it less extensively than the wild type. With the other mutants, few (peak, ragged) or no bursts (colonial-2, crisp, frost, balloon) were observed. Seemingly, the bursting tendency is correlated with the spreading ability of the mycelium (i.e. hyphal elongation rate) for only the wild-type and the two mutants, ropy and pile, with smaller but clearly spreading colonies were prone to bursting.

Schizophyllum commune and four species of Phytophthora (Phytophthora palmivora, $P$. cinnamomi, P. megasperma and P. parasitica; grown on IX.YPG or V-8 agar showed no evidence of apical bursting when flooded with distilled water. 
Table 2. Rate and temperature coefficient of hyphal tip bursting upon flooding with distilled water

\begin{tabular}{|c|c|c|c|c|}
\hline \multirow[b]{2}{*}{ Temperature } & \multicolumn{2}{|c|}{ Mucor rouxii } & \multicolumn{2}{|c|}{ Neurospora crassa } \\
\hline & $\begin{array}{l}\text { Bursting } \\
\text { time }(s) *\end{array}$ & $Q_{10}$ & $\begin{array}{l}\text { Bursting } \\
\text { time }(s) *\end{array}$ & $\mathrm{Q}_{10}$ \\
\hline $\begin{array}{r}5{ }^{\circ} \mathrm{C} \\
15{ }^{\circ} \mathrm{C} \\
25^{\circ} \mathrm{C}\end{array}$ & $\left.\begin{array}{l}30.2 \\
14.7 \\
10.7\end{array}\right\}$ & $\begin{array}{l}2 \cdot 03 \\
1 \cdot 37\end{array}$ & $\left.\begin{array}{r}\text { I33.5 } \\
77.6 \\
44.5\end{array}\right\}$ & $\begin{array}{l}I \cdot 72 \\
I \cdot 78\end{array}$ \\
\hline
\end{tabular}

* The most frequent time of bursting (mode) was obtained by interpolation from a frequency distribution graph of bursting times; data were grouped at $3 \mathrm{~s}$ intervals for Mucor rouxii, and $20 \mathrm{~s}$ intervals for Neurospora crassa. Colonies were grown for 13.5 to $17.5 \mathrm{~h}$ on $1 \mathrm{X}$. YPG agar for $M$. rouxii and $\mathrm{I} 7$ to $23 \mathrm{~h}$ for N. crassa.

In Mucor rouxii (Fig. 3, 4), Rhizopus arrhizus and Aspergillus fumigatus, bursting occurred mainly through the apical dome and rarely behind it; in Neurospora crassa (Fig. 5) or Penicillum claviforme, the cytoplasm was also frequently extruded immediately behind the apical dome and in $N$. crassa, sometimes through the lateral walls. Occasionally, bursting was observed in an intercalary hyphal segment. Rizvi \& Robertson (I965) also found that hyphal disintegration in Neurospora crassa was slightly subapical.

\section{Temperature coefficient of bursting}

The effect of temperature on apical bursting was assessed by flooding the plates of Mucor rouxii or Neurospora crassa with running distilled water at $5, \mathrm{I} 5$ and $25^{\circ} \mathrm{C}$. A single microscopic field ( $\times$ I 0 objective) focused on the periphery of a colony, containing an average of 40 hyphal tips of $M$. rouxii (fewer for $N$. crassa), was maintained under continuous observation and the rupture time of each hyphal tip was scored. Twelve to fifteen plates were examined at each temperature. Bursting rates were compared by determining the most frequent time of bursting (mode) at each temperature (Table 2). At any given temperature the hyphal tips of $M$. rouxii burst much more rapidly than those of $N$. crassa but in either fungus the speed of bursting was highly dependent on the temperature of the flooding water. Modal time of bursting decreased with increasing temperature. Temperature coefficient values were higher than $\mathrm{I} \cdot \mathrm{O}$ for both fungi (Table 2 ).

\section{Apex bursting of Mucor rouxii by flooding with various solutions}

Acids. Dilute solutions of inorganic and organic acids were effective promoters of apical bursting. Application of 0.00 I $\mathrm{M}$ solutions of sulphuric acid, phosphoric acid, acetic acid and citric acid, or carbonated water caused a rapid, massive disintegration of the growing tips of Mucor rouxii in colonies grown on X/16. YPG medium (Fig. 6, 7). The acids were effective in the range $0 \cdot 00 \mathrm{I}$ to $0^{\cdot} \mathrm{I} \mathrm{M}$. At higher concentrations, bursting was probably avoided because of osmotic protection.

The $\mathrm{pH}$ range conducive to apical disintegration was determined by using a $0.01 \mathrm{M}$-acetic acid solution adjusted to various $\mathrm{pH}$ values with $\mathrm{NaOH}$ or $\mathrm{NH}_{4} \mathrm{OH}$ (Table 3). Bursting decreased significantly at $\mathrm{pH}$ values above 4.5 to $5^{\circ} \mathrm{O}$ and ceased at 5.5 to 6.0 under the conditions of the experiment. The response varied slightly from experiment to experiment probably reflecting minor changes in conditions.

Alkalis. In most instances alkaline solutions inhibited or failed to elicit apex bursting (Table 4). Thus, the hyphal tips of colonies of Mucor rouxii grown on IX. YPG agar burst 


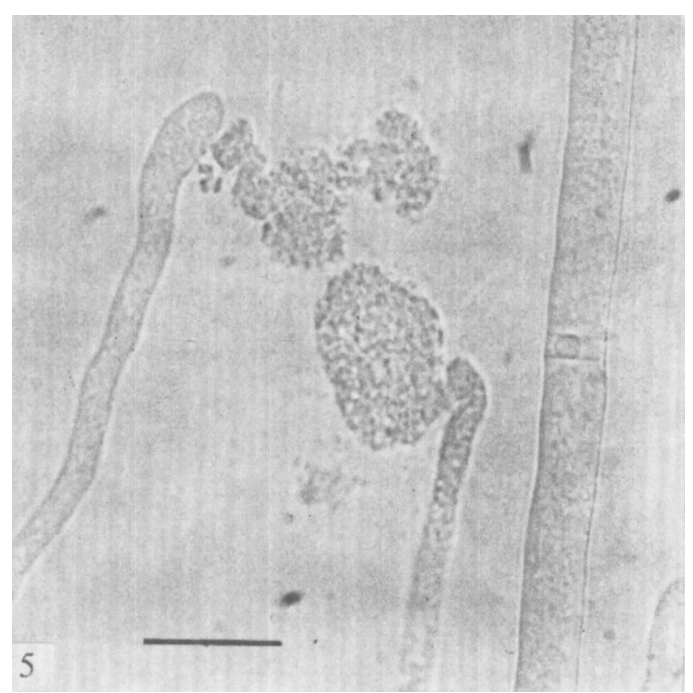

Fig. 5. Burst hyphal tips of Neurospora crassa (wild-type). Colony grown on IX.YPG and flooded with drops of distilled water. (Scale marker $=20 \mu \mathrm{m}$.)
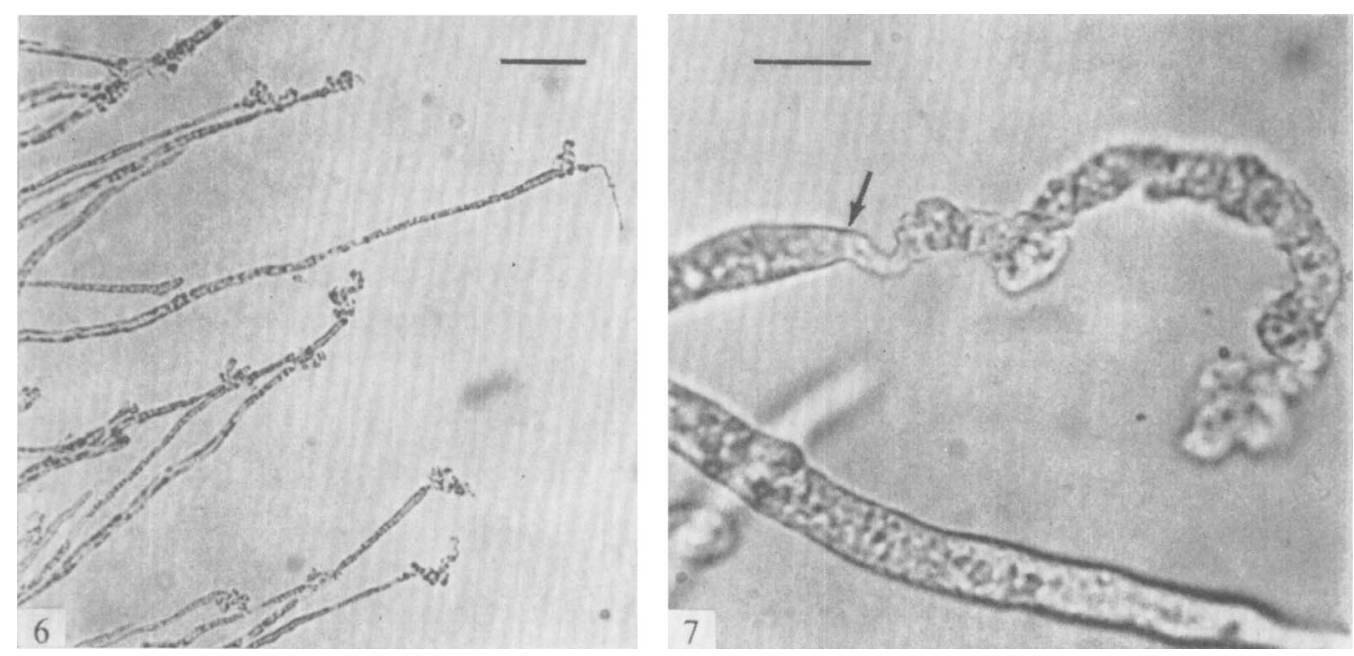

Fig. 6,7. Bursting of hyphal tips of Mucor rouxii with $0 . \mathrm{I}$ M-acetic acid. Arrow points at site of bursting. Colony grown on X/16. YPG. (Scale markers $=30 \mu \mathrm{m}$, Fig. 6 ; and $10 \mu \mathrm{m}$, Fig. 7.)

more slowly and less extensively when flooded with dilute solutions of $\mathrm{NaOH}$ or $\mathrm{KOH}$ ( $0.00 \mathrm{I}$ to $0 . \mathrm{I} \mathrm{M}$ ) than with water. $\mathrm{NH}_{4} \mathrm{OH}$ also inhibited bursting at low concentrations ( $0.00 \mathrm{I}$ to $0.0 \mathrm{I} \mathrm{M})$ but, surprisingly, not at higher concentrations $(0.05$ to $\mathrm{I} \cdot 0 \mathrm{M})$. With 2aminoethanol, slow but extensive apex bursting occurred at $\mathrm{O} \cdot \mathrm{I} \mathrm{M}$ but at other concentrations there was complete inhibition.

Tests on colonies grown on X/16. YPG plates failed to show bursting in response to flooding with $\mathrm{KOH}$ or $\mathrm{NaOH}$ solutions (molarity range: $0.00 \mathrm{I}$ to $\mathrm{I} \cdot 0$; $\mathrm{pH}$ range: about 9 to 13.5). Yet, at certain concentrations, $\mathrm{NH}_{4} \mathrm{OH}$ or 2-aminoethanol caused apical bursting (Table 4). It seems unlikely that these apical disintegrations were caused by the alkalinity of 
Table 3. Effect of pH on apex bursting in Mucor rouxii

Colonies ( 1 i to $12 \mathrm{~h}$ old) grown on X/16. Y PG agar were flooded with $20 \mathrm{ml}$ of acetic acid solutions adjusted to each $\mathrm{pH}$ value with either $\mathrm{NaOH}$ or $\mathrm{NH}_{4} \mathrm{OH}$.

Flooding solutions

\begin{tabular}{|c|c|c|c|c|}
\hline \multirow[b]{2}{*}{$\mathrm{pH}$} & \multicolumn{2}{|c|}{0.01 m-acetic acid $+1 \mathrm{~m}-\mathrm{NaOH}$} & \multicolumn{2}{|c|}{$0.0 \mathrm{I}$ m-acetic acid + I M- $\mathrm{NH}_{4} \mathrm{OH}$} \\
\hline & Intensity* & Rapidity & Intensity* & Rapidity \\
\hline $3 \cdot 4$ & $++t$ & $2 \mathrm{~s}$ & ++++ & 2 to $3 \mathrm{~s}$ \\
\hline 4.0 & ++++ & 2 to $3 \mathrm{~s}$ & ++++ & 2 to $3 \mathrm{~s}$ \\
\hline $4 \cdot 6$ & $+t+t$ & 2 to $3 \mathrm{~s}$ & $+++t$ & 3 to $4 \mathrm{~s}$ \\
\hline $5 \cdot 0$ & +++ & 2 to $3 \mathrm{~s}$ & +++ & $5 \mathrm{~s}$ \\
\hline $5 \cdot 5$ & ++ & $5 \mathrm{~s}$ & \pm & \\
\hline $6 \cdot 0$ & - & & - & \\
\hline
\end{tabular}

* The intensity of the reponse was scored as follows: $(++++)$ most of the tips burst; $(+++)$ over one-half of the tips burst; $(++)$ about one-third burst; $(+)$ only a few tips burst; $( \pm)$ a rare burst on the entire colony; $(-)$ none.

$\succ$ Rapidity refers to the approximate time for initiation of bursting.

Table 4. Apex bursting of Mucor rouxii flooded with alkaline solutions

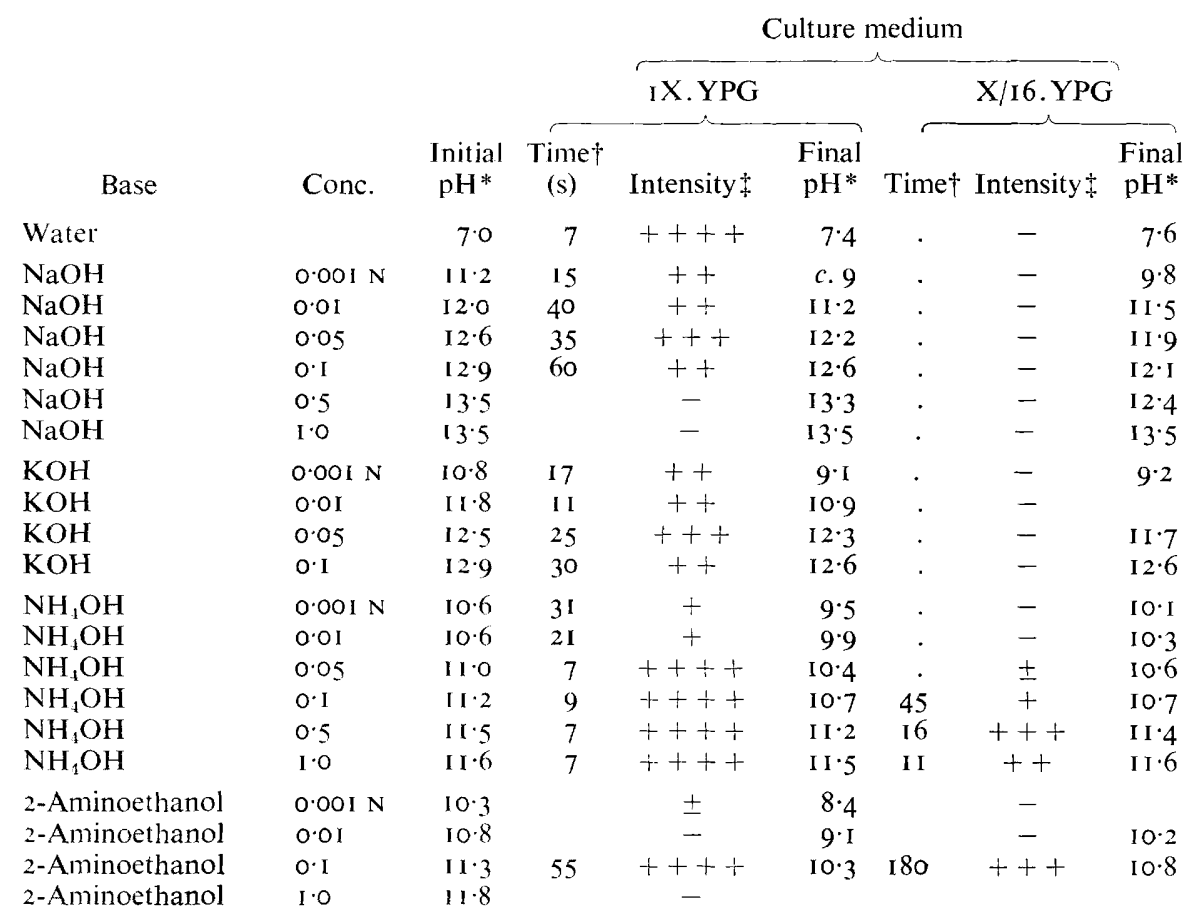

* Initial pH of flooding solution was determined with a Corning triple-purpose glass electrode. Final pH was determined after the flooding solution was in contact with the agar for 5 to Io min.

$\rightarrow$ Approximate time of initiation of the bursting response.

Intensity score as in Table 3 . 

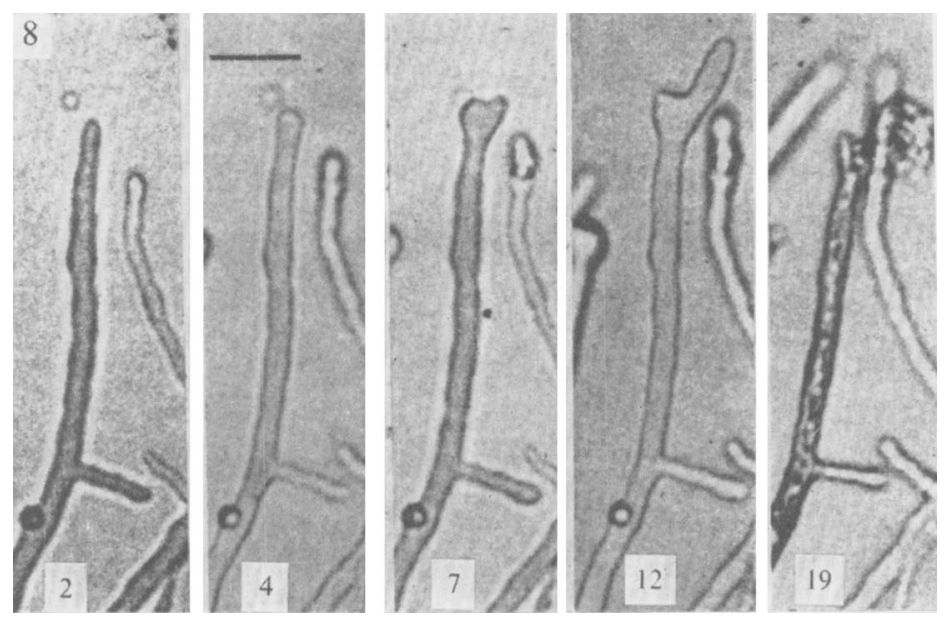

Fig. 8. Apical swelling and bursting of a hyphal tip of Mucor rouxii flooded with $0.01 \mathrm{M}-\mathrm{MnCl}_{2}$. Colony grown on $\mathrm{X} / 16$. YPG. Numbers indicate incubation time (min) after flooding. The apical burst shown at $19 \mathrm{~min}$ is a rare event in colonies thus treated. (Scale marker $=25 \mu \mathrm{m}$.)

the external medium, since $\mathrm{KOH}$ or $\mathrm{NaOH}$ was ineffective at the same $\mathrm{pH}$ range. Possibly, the action of $\mathrm{NH}_{4} \mathrm{OH}$ and 2-aminoethanol was related to their ability to diffuse across the permeability barrier of the fungus.

Neutral salts. Although the response was not as rapid or extensive as that attained with the acids, flooding with neutral salt solutions also caused disintegration of the hyphal tips in colonies grown for about $12 \mathrm{~h}$ on $\mathrm{X} / \mathrm{I} 6$. YPG. Bursting occurred only in a narrow concentration range of the salt. Thus while flooding with $0.05 \mathrm{M}-\mathrm{NaCl}$ produced many bursts per field, flooding with $0.0 \mathrm{I}$ or $0 . \mathrm{I} \mathrm{M}-\mathrm{NaCl}$ had little or no effect. Solutions of $\mathrm{KCl}$, potassium phosphate $\left(\mathrm{K}_{2} \mathrm{HPO}_{4}+\mathrm{KH}_{2} \mathrm{PO}_{4} ; \mathrm{pH} 6.8\right)$ or sodium phosphate $\left(\mathrm{Na}_{2} \mathrm{HPO}_{4}+\mathrm{NaH}_{2} \mathrm{PO}_{4} ; \mathrm{pH} 6.8\right)$ manifested essentially the same effects.

Miscellaneous. A number of other compounds were capable of eliciting bursting in colonies of Mucor rouxii grown on X/16. YPG. Aqueous solutions (10 \%, v/v) of methanol, ethanol, and acetone and detergents, such as sodium dodecyl sulphate (0. I to $0.5 \mathrm{~mm}$ at $\mathrm{pH} 6$ or 8$)$ and Tween $80(0.5 \%$ solution at $\mathrm{pH} 3.5,4.5,5.8$ but not 6.9$)$ were effective. Sulphydrylcontaining compounds (O.Or or $0.1 \mathrm{M})$, e.g. glutathione and dithiothreitol, caused few bursts whereas mercaptoethanol was ineffective. EDTA (0.00I or $0.0 \mathrm{I} \mathrm{M} ; \mathrm{pH} 5$ to 7 ) was highly effective.

\section{Apex swelling of Mucor rouxii by divalent metals}

Contrary to the action of monovalent metals, chloride solutions of $\mathrm{Mg}^{2+}, \mathrm{Mn}^{2+}$ or $\mathrm{Ca}^{2+}$ caused little or no apical bursting on colonies of Mucor rouxii grown for about $\mathrm{I} 2 \mathrm{~h}$ on $\mathrm{X} / \mathrm{I} 6$. YPG agar. Instead, there was pronounced apical 'swelling'. Almost all growing tips developed swellings of various shapes (spherical, ellipsoidal, pyriform) within a few minutes after flooding with $0.0 \mathrm{I}$ to $0.075 \mathrm{M}$ solutions of the above salts (Fig. 8). On prolonged incubation one or sometimes two hyphal tubes emerged from the swelling. This behaviour resembled that described by Robertson (1958) for hyphal tips in colonies of Fusarium oxysporum flooded with distilled water. Occasionally a swollen tip burst (Fig. 8). 


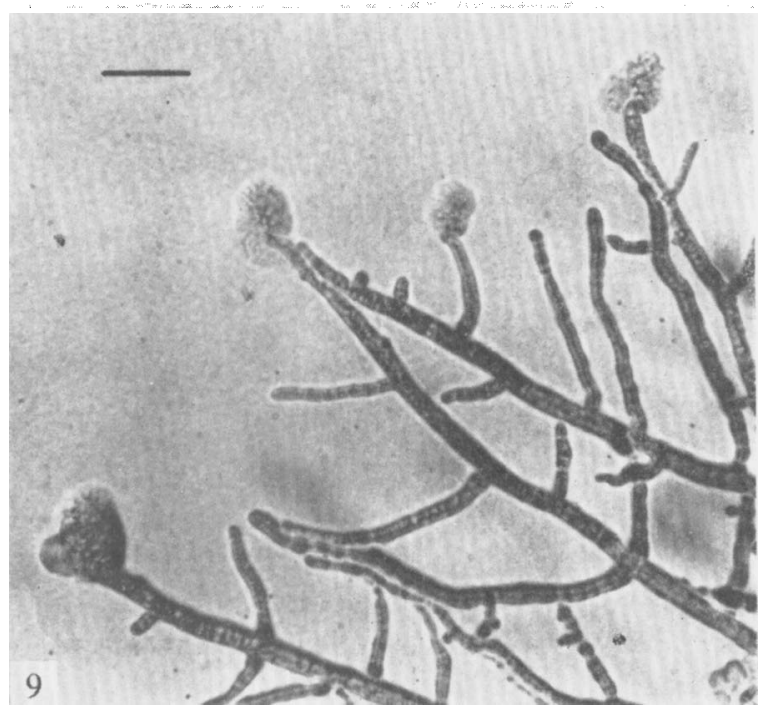

Fig. 9. Bursting of hyphal tips of Mucor rouxii by heat shock. Colony grown on IX.YPG at $28^{\circ} \mathrm{C}$ transferred to oven at $\mathrm{I} 60^{\circ} \mathrm{C}$ for I min. (Scale marker $=30 \mu \mathrm{m}$.)

\section{Apex bursting by heat shock}

Rapid heating of a colony of Mucor rouxii grown on IX. YPG agar by placing plastic Petri dish cultures in a forced-circulation oven caused estensive bursting of the hyphal tips. Massive apical bursting occurred after $2 \mathrm{~min}$ heating at $95{ }^{\circ} \mathrm{C}$ or I $\min$ at $\mathrm{I} 60^{\circ} \mathrm{C}$ (Fig. 9). At lower oven temperatures $\left(50\right.$ to $95^{\circ} \mathrm{C}$ ) the frequency of bursting diminished accordingly. At $50^{\circ} \mathrm{C}$ only a rare burst was recorded after $15 \mathrm{~min}$ of heating. No attempt was made to measure the temperature attained by the agar surface in all these incubations but the temperature must have risen rapidly and continuously for bursting to have occurred. Thus, if a plate was mildly preheated $\left(52{ }^{\circ} \mathrm{C}\right.$ for $\left.5 \mathrm{~min}\right)$, cooled at room temperature for $5 \mathrm{~min}$ and then heated at $95{ }^{\circ} \mathrm{C}$ for $2 \mathrm{~min}$, essentially no bursting occurred.

Primary or secondary hyphal tips were susceptible to bursting by oven heating. Colonies grown on either X/16. YPG or IX.YPG media were susceptible to bursting by heat shock but the extent of bursting was greater in the latter medium.

Heating also resulted in apex bursting in Aspergillus fumigatus, Penicillium claviforme, Fusarium sp., but not in Phytophthora cinnamomi, $P$. palmivora nor $P$. parasitica. Thus, fungi prone to bursting by osmotic shock, also burst by heat shock

A mild heat shock could also elicit bursting. Some of the peripheral hyphae from colonies of Mucor rouxii grown on IX.YPG at 6 or $15{ }^{\circ} \mathrm{C}$ burst when the plates were transferred to either 25 or $36^{\circ} \mathrm{C}$. The reverse transfers (cold shock) did not cause any bursting.

The disintegration of hyphal tips by heat could be nullified by osmotic balance. Thus whereas pouring boiling water on to colonies of Mucor rouxii grown on either IX.YPG or $\mathrm{X} / \mathrm{I} 6$. YPG caused extensive bursting, boiling solutions of $0.5 \mathrm{M}$-mannitol had no effect.

\section{Spontaneous bursting of hyphal tips of Mucor rouxii}

On careful examination, an occasional burst hyphal tip was seen on the margin of a colony of Mucor rouxii which had not been subjected to any exogenous disturbance. These plates had been incubated continuously under constant conditions and were examined im- 
mediately after being removed from the incubator. Seemingly bursting could occur during the normal course of colony development. No effort was made to determine the frequency of spontaneous bursts nor the cultivation conditions affecting it.

\section{DISCUSSION}

Our findings confirm and expand previous reports on the proneness of hyphal tips of fungi to burst on addition of distilled water (Robertson, I958, I959) or dilute acetic acid (Park \& Robinson, 1966a). At first sight, the bursting of hyphal tips upon exposure to water or hypotonic solutions might simply appear as an osmotic phenomenon - the hyphal walls, unable to withstand the sudden drop in external pressure, burst at their weakest zone, the growing tip. However, our findings indicate that the osmotic shock is not the key or sole cause of bursting. Active weakening of the apical wall seems also to be essential. If bursting upon addition of distilled water were purely an osmotic phenomenon, it would show a temperature coefficient near $\mathrm{I} \cdot \mathrm{O}$. The higher values observed (from $\mathrm{I} \cdot 3$ to $2 \cdot 05$ ) indicate the participation of a biochemical reaction(s), as the rate-limiting step in the bursting process. Presumably this biochemical reaction is one which weakens the wall to the point where it can no longer withstand the turgor of the cytoplasm.

The osmotic shock caused by addition of distilled water to a colony grown on X/16. YPG agar was insufficient to cause bursting of the apices. Yet, these hyphal tips were capable of bursting when flooded with dilute aqueous solutions of neutral salts or acids. Clearly, bursting did not occur simply because the wall failed to withstand the sudden decrease in external osmotic pressure; active weakening of the wall must have occurred, triggered by the various solutes present in the flooding water. Because of the diversity of agents triggering bursting (acids, neutral salts, alcohols, detergents, heat etc.) it seems improbable that this weakening effect is a direct chemical attack on the wall polymers by the agent in question (though this might also occur, as for example, in high-acidity treatments). More likely the effect is on wall metabolism.

The present observations constitute circumstantial evidence to support the following contentions: (i) the apices of fungal hyphae have a large potential of wall lytic activity; (ii) the release of this activity during growth must be a gradual process delicately co-ordinated with wall synthesis; (iii) the balance between synthesis and lysis of wall polymers can be easily disturbed and shifted in favour of lysis by a variety of external stimuli resulting in violent disintegration of the hyphal apex or, under certain conditions, the formation of large apical 'swellings'.

The need for at least two counterbalancing processes operating during apical wall construction has been recognized by others and formulated in similar or somewhat different terms (Robertson, 1965; Park \& Robinson, 1966 b; Green, 1969).

The equilibrium in wall metabolism, advocated herein, could be displaced in the direction of wall degradation by either an increase in wall lysis or a decrease in wall synthesis. Presumably such were the specific effects elicited by external application of a wallsplitting enzyme (lysozyme) or an inhibitor of wall synthesis (polyoxin D), respectively. Lysozyme, an enzyme with chitinase activity (Berger \& Weiser, I957), causes extensive and rapid bursting of hyphal tips of Mucor rouxii (Bartnicki-Garcia \& Lippman, in preparation). Likewise, application of polyoxin $\mathrm{D}$, an antibiotic which specifically inhibits chitin synthesis (Endo, Kakiki \& Misato, I970), results in bursting of hyphal apices of M. rouxii (BartnickiGarcia \& Lippman, 1972). Similar conclusions can be made from other observations on fungal behaviour. For instance, digestion with hydrolytic enzymes causes apical disintegration of 
hyphae of Neurospora crassa (Rizvi \& Robertson, 1965). Likewise, protoplasts of different fungi, prepared by enzymatic digestion, are frequently seen emerging through the hyphal tips (Gascón, Ochoa \& Villanueva, 1965; Bartnicki-Garcia \& Lippman, 1966; Strunk, 1969). In yeast cells, 2-deoxyglucose, an inhibitor of the synthesis of wall hexosans (Farkaš, Svoboda \& Bauer, I969) causes cell lysis (Megnet, 1965). Significantly, the yeast cells lyse at the same sites where wall synthesis is believed to take place (Johnson, 1968). Similarly, the distintegration of hyphal apices of a mutant of Neurospora crassa, which occurs upon treatment with L-sorbose, is thought to be due to interference with the production of wall glucan (Rizvi \& Robertson, 1965).

The facility with which hyphal tips undergo bursting suggests that the postulated balance between wall synthesis and wall lysis must be rather precarious and can readily drift in the direction of lysis. This may even occur during the normal growth of a hypha and would explain the occurrence of spontaneously burst hyphae in a seemingly undisturbed colony of Mucor rouxii.

Most of the fungi examined exhibited a marked propensity to undergo apical bursting by either 'osmotic' (flooding with water) or heat shock, but not Phytophthora sp. or Schizophyllum commune. Only treatment with O.I M-acetic acid caused an occasional burst in Phythophthora spp. The greater resistance of these fungi to bursting may reflect a greater metabolic stability of the apical wall.

Two different but not mutually exclusive mechanisms may be invoked to explain how widely different bursting agents may interact with apical wall metabolism:

(I) Effect on enzyme activity. The treatments may drastically alter the milieu where wall synthetases and wall-splitting enzymes operate and thus upset their mutual balance. There is evidence that some polysaccharide synthetases (Wang \& Bartnicki-Garcia, 1966; McMurrough, Flores-Carreón \& Bartnicki-Garcia, I97I; Mishra \& Tatum, 1972) as well as polysaccharide hydrolases (Mahadevan \& Mahadkar, 1970) are intimately associated with the fungal wall and would thus be exposed to the environment. Changes in $\mathrm{pH}$, ionic strength, and temperature are apt to inhibit polysaccharide synthetases preferentially over the more environmentally resistant hydrolases, thus allowing degradative processes to prevail. The high susceptibility of chitin synthetase of Mucor rouxii to changes in $\mathrm{pH}$, ionic strength, and temperature (McMurrough \& Bartnicki-Garcia, I97I) compared to the considerably more stable properties of chitin hydrolases isolated from other fungi (Tracey, 1955; Otakara, I96I) makes this explanation plausible.

(2) Effect on enzyme release. Conceivably, the treatments leading to bursting augment or provoke the discharge of vesicles containing autolytic enzymes. The observation that bursting is not always strictly apical but may occur subapically, or laterally, or that large apical swellings may be produced instead of, or before, bursting, suggest that the lytic activity is not necessarily restricted or fixed to the apical-dome wall. Conceivably, it resides initially in the cytoplasm, possibly in apical vesicles such as those seen by Brenner \& Carroll (I968), McClure, Park \& Robinson (1968), Girbardt (I969) and Grove \& Bracker (I970). Although the contents of these vesicles are not known, some of them may harbour hydrolytic enzymes. Thus $\beta$-I,3-glucanase has been localized in vesicular elements of Saccharomyces cerevisiae comparable to the vesicles of hyphal tips (Matile, Cortat, Wiemken \& Frey-Wyssling, I97I). During growth, apical vesicles are produced continuously, fuse with the plasma membrane and liberate their contents into the wall region (Grove, Bracker \& Morré, 1970). We propose, then, that apical bursting may occur when an inordinately high proportion of lytic vesicles are forced to discharge their contents against the wall. This interpretation is in accord with cytological observations showing the pronounced lability of the vesicular apparatus in 
hyphal tips (Girbardt, I957, I969; Bracker, I97I ; Grove, I97I). For instance, mere washing of germinating cells of Gilbertella persicaria caused the disappearance of the apical vesicles (Bracker, I97I) and the formation of lomasome-like deposits under the cell wall. Since the highest concentration of vesicles occurs in the apical dome, this would be the zone most severely and rapidly degraded and, hence, the most frequent site of bursting, but the vesicles may also migrate to a subapical region causing a cytoplasmic discharge immediately below the apical dome or even further behind on the lateral walls. Some of the observed discharges of cytoplasm through lateral hyphal walls were probably at sites where branches were about to emerge and where the enzymatic machinery for apical growth was already congregated.

Flooding with divalent metal ions $\left(\mathrm{Mg}^{2+}, \mathrm{Mn}^{2+}, \mathrm{Ca}^{2+}\right)$ may cause only a partial increase in wall lytic activity - insufficient to weaken the wall to its bursting point but enough to temporarily increase the 'plastic' area of the growing apex thereby giving rise to a 'swollen' tip.

The participation of wall autolytic enzymes in morphogenetic processes of fungi seems indispensable in phenomena like hyphal anastomosis, clamp connection and sexual fusions which involve dissolution of walls. But it is probably true in less obvious ones. Nickerson \& Falcone (1956) gathered experimental evidence for the operation of a protein disulphide reductase as a key step in plasticizing localized areas of the yeast wall where budding was to take place. Regarding apical growth, it is unlikely that the turgor pressure of the cytoplasm could account for the spatially restricted expansion of the growing apical wall (Green, I969). The localized participation of wall-splitting enzymes in the growth zone is highly probable. Additional evidence implicating wall-splitting enzymes in apical growth lies in the correlation between the initiation of apical growth (e.g. branching, conidium germination) and an increase in wall-bound hydrolases (Mahadevan \& Mahadkar, 1970; Mahadevan \& Rao, 1970). Recently, Katz \& Rosenberger (197I $b$ ), studying the lysis of a mutant of Aspergillus nidulans blocked in chitin synthesis, concluded that enzymes that open bonds in the wall and generate weak regions are an integral part of the normal growth process.

In a previous communication, we demonstrated the existence of a sharp gradient of wall synthesis in the hyphal tips of Mucor rouxii and speculated on the need for a parallel gradient of wall lysis (Bartnicki-Garcia \& Lippman, 1969). Although it has not been possible to directly demonstrate the existence of such a gradient, the present findings suggesting the existence of concentrated wall-lytic activity in the hyphal apex, strengthen the belief that autolytic enzymes play a role in hyphal development.

\section{REFERENCES}

Bartnicki-Garcia, S. \& Lippman, E. (1966). Liberation of protoplasts from the mycelium of Phytophthora. Journal of General Microbiology 42, 4I I-4I 6.

Bartnicki-Garcia, S. \& LippMan, E. (1969). Fungal morphogenesis: Cell wall construction in Mucor rouxii. Science, Washington $\mathbf{1 6 5}, 302-304$.

Bartnicki-Garcia, S. \& Lippman, E. (I972). Inhibition of Mucor rouxii by polyoxin D: effects on chitin synthetase and morphological development. Journal of General Microbiology 71, 30I-309.

BERGER, L. R. \& WEISER, R. S. (I957). The $\beta$-glucosaminidase activity of egg-white lysozyme. Biochimica et biophysica acta 26, 51 7-52 I.

BrACKER, C. E. (1971). Cytoplasmic vesicles in germinating spores of Gilbertella persicaria. Protoplasma $\mathbf{7 2 ,}$ $38 \mathrm{I}-397$.

Brenner, D. M. \& Carroll, G. C. (1968). Fine-structural correlates of growth in hyphae of Ascodesmis sphaerospora. Journal of Bacteriology 95, 658-671.

Brody, S. (1972). Metabolism, cell walls and morphogenesis. In Cell Differentiation. Edited by S. Coward. New York: Academic Press. (In the press.) 
ENDO, A., KAKIKI, K. \& Misato, T. (I970). Mechanism of action of the antifungal agent polyoxin D. Journal of Bacteriology ro4, I 89-196.

FARKAŠ, V., Svoboda, A. \& BAUER, S. (1969). Inhibitory effect of 2-deoxy-D-glucose on the formation of the cell wall in yeast protoplasts. Journal of Bacteriology $\mathbf{9 8}, 744-748$.

Gascón, S., Ochoa, A. G. \& Villanueva, J. R. (I965). Production of yeast and mold protoplasts by treatment with the strepzyme of Micromonospora AS. Canadian Journal of Microbiology rI, 573-580.

Girbardt, M. (1957). Der Spitzenkörper von Polystictus versicolor. Planta 50, 47-59.

Girbardt, M. (I969). Die Ultrastruktur der Apikalregion von Pilzhyphen. Protoplasma 67, 4I 3-44I.

GOODAY, G. W. (I97I). An autoradiographic study of hyphal growth of some fungi. Journal of General Microbiology 67, I25-133.

Green, P. B. (1 969). Cell morphogenesis. Annual Review of Plant Physiology 20, 365-394.

Grove, S. N. (197I). Protoplasmic correlates of hyphal tip initiation and development in fungi. Ph.D. Thesis, Purdue University, Lafayette, Indiana, U.S.A.

Grove, S. N. \& Bracker, C. E. (1970). Protoplasmic organization of hyphal tips among fungi: vesicles and Spitzenkörper. Journal of Bacteriology 104, 989-1009.

Grove, S. N., Bracker, C. E. \& Morré, D. J. (1970). An ultrastructural basis for hyphal tip growth in Pythium ultimum. American Journal of Botany 57, 245-266.

Johnson, B. F. (I968). Lysis of yeast cell walls induced by 2-deoxyglucose at their sites of glucan synthesis. Journal of Bacteriology 95, I $169-1 \mathrm{I} 72$.

Katz, D. \& Rosenberger, R. F. (I971 $a$ ). Hyphal wall synthesis in Aspergillus nidulans: effect of protein synthesis inhibition and osmotic shock on chitin insertion and morphogenesis. Journal of Bacteriology 108, I 84-190.

KATZ, D. \& Rosenberger, R. F. (I97I b). Lysis of an Aspergillus nidulans mutant blocked in chitin synthesis and its relation to wall assembly and wall metabolism. Archiv für Mikrobiologie 8o, 284-292.

McClure, W. K., Park, D. \& Robinson, P. M. (I968). Apical organization in the somatic hyphae of fungi. Journal of General Microbiology 50, 177-182.

McMurrough, I. \& Bartnicki-Garcia, S. ( 197I). Properties of a particulate chitin synthetase from $\mathrm{Mucor}$ rouxii. Journal of Biological Chemistry 246, 4008-4016.

McMurrough, I., Flores-Carreón, A. \& Bartnicki-Garcia, S. (i97i). Pathway of chitin synthesis and cellular localization of chitin synthetase in Mucor rouxii. Journal of Biological Chemistry 246, 39994007 .

MahadeVAn, P. R. \& Mahadkar, U. R. ( I970). Role of enzymes in growth and morphology of Neurospora crassa: cell-wall-bound enzymes and their possible role in branching. Journal of Bacteriology Ior, 94 I947.

MahadeVAn, P. R. \& RaO, S. R. (I970). Enzyme degradation of conidial wall during germination of Neurospora crassa. Indian Journal of Experimental Biology 8, 293-297.

Matile, P., Cortat, M., Wiemken, A. \& Frey-Wyssling, A. (197I). Isolation of glucanase-containing particles from budding Saccharomyces cerevisiae. Proceedings of the National Academy of Sciences of the United States of America 68, 636-640.

MEGNET, R. (1965). Effect of 2-deoxyglucose on Schizosaccharomyces pombe. Journal of Bacteriology 9o, $1032-1035$.

Mishra, N. C. \& TATUM, E. L. (1972). Effect of L-sorbose on polysaccharide synthetases of Neurospora crassa. Proceedings of the National Academy of Sciences of the United States of America 69, 313-3I7.

Nickerson, W. J. \& FAlCONE, G. (1956). Identification of protein disulfide reductase as a cellular division enzyme in yeasts. Science, Washington 124, 722-723.

Otakara, A. (I96I). Studies on the chitinolytic enzymes of black-koji mold. III. Liquefying activity and saccharifying activity of the chitinase preparation. Agricultural and Biological Chemistry 25, 494-499.

PARK, D. \& RoBINSON, P. M. (I966a). Internal pressure of hyphal tips of fungi, and its significance in morphogenesis. Annals of Botany 30, 425-439.

Park, D. \& Robinson, P. M. (1966b). Aspects of hyphal morphogenesis in fungi. In Trends in Plant Morphogenesis, pp. 27-44. Edited by E. G. Cutter. London: Longmans, Green \& Co.

REINHARDT, M. O. (1892). Das Wachstum der Pilzhyphen. Jahrbuch für wissenschaftliche Botanik 23, 479566.

Rizvi, S. R. H. \& Robertson, N. F. (1965). Apical disintegration of hyphae of Neurospora crassa as a response to L-sorbose. Transactions of the British Mycological Society 48, 469-477.

RoBERTSON, N. F. (1958). Observations on the effect of water on the hyphal apices of Fusarium oxysporum. Annals of Botany 22, I 59-I 73. 
ROBERTSON, N. F. (1959). Experimental control of hyphal branching and branch form in hyphomycetous fungi. Journal of the Linnean Society 56, 207-2I I.

ROBERTSOn, N. F. (1965). The fungal hypha. Transactions of the British Mycological Society 48, I-8.

SмIтH, J. H. (1923). On the apical growth of fungal hyphae. Annals of Botany 37, 34I-343.

STRUNK, C. (1969). Licht- und elektronenmikroskopische Untersuchungen an jungen Protoplasten von Polystictus versicolor. Zeitschrift für allgemeine Mikrobiologie 9, 49-60.

TRACEY, M. V. (1955). Chitinase in some Basidiomycetes. Biochemical Journal 6r, 579-586.

WANG, M. C. \& BARTNICKI-GARCIA, S. (1966). Biosynthesis of $\beta-1,3$ and $\beta-\mathrm{I}, 6$-linked glucan by Phytophthora cinnamomi hyphal walls. Biochemical and Biophysical Research Communications 24, 832-837. 